\title{
Student experience of hub and spoke model of placement allocation - An evaluative study
}

\author{
Megan Thomas *, Nicky Westwood \\ University of Wolverhampton, Faculty of Education, Health and Wellbeing, Gorway Rd, Walsall, West Midlands WS13BD, United Kingdom
}

\section{A R T I C L E I N F O}

\section{Article history:}

Received 4 November 2015

Received in revised form 28 July 2016

Accepted 15 August 2016

\section{Keywords:}

Nursing practice

Clinical placements

Placement pathways

Practice assessment

Hub and spoke nursing

Practice learning

\begin{abstract}
A B S T R A C T
An evaluative project was undertaken at the University of Wolverhampton centring on the Hub and Spoke model utilised for organisation of placement allocation across the BNurs programme for all fields of nursing. Student experience was of particular interest throughout the evaluation with the research team focusing on the views, feelings and experiences of student nurses in relation to the hub and spoke model applied for practice. A qualitative approach was adopted, initially using Survey Monkey to collect student views through a series of open questions, and further enhanced by focus groups. These were transcribed and together with the data from the surveys, data was categorized and themed. Themes were analysed and conclusions drawn.

The hub and spoke method for placements was found to enhance student understanding of the whole patient journey which offered students a wide breadth of experience and development of transferable skills such as communication and adaptability. A sense of increased belonging was highlighted by students which encouraged the development of strong effective relationships positively affecting their learning. Some less positive aspects were apparent revolving around personality difficulties and organisational problems, in particular relating to spoke placements. The purpose of spoke placements was not always apparent and sometimes there was a lack of appropriate student placement experiences provided by spoke mentors. Overall the hub and spoke model for organising placement was found to be beneficial and enhanced the student's experience, satisfaction and learning, which in turn had a positive effect on practice.
\end{abstract}

C 2016 Published by Elsevier Ltd.

\section{Introduction}

This paper considers the experiences, views and feelings of students on the BNurs programme in relation to practice placements. Placements are organised through a system of hub and spoke. Here, student nurses are allocated to one hub placement per year for the practice component of the curriculum. They return to the hub on 3 separate occasions throughout the academic year for blocks of placement. To further enhance their placement experience students are allocated to "spoke" placements which can be from 1 to 4 weeks. Spoke placements are linked closely to the speciality area of the hub and reflect the patients journey across healthcare settings.

The research was led by a group of university academics, practice partners, student advisors and academic staff who spend $50 \%$ of their time working in practice. A qualitative approach was taken to gain the feelings and experiences of students relating to practice organisation. Data collection methods included qualitative surveys and focus groups. Although a few students felt that some spoke placements did not enable effective learning, others found that they supported a breadth of

\footnotetext{
* Corresponding author.

E-mail addresses: M.P.Thomas@wlv.ac.uk (M. Thomas), Nicky.Westwood@wlv.ac.uk (N. Westwood).
}

knowledge, experience and learning which increased their confidence within the practice setting. From the data, it was apparent that the model of organising placements enabled participants view the whole patient journey.

This paper will consider literature relevant to student nurse placement, detail the data collection methods and present the findings from the project. Finally, the results will be discussed, conclusions drawn and recommendations for future practice identified.

\section{Literature Review}

Pre-registration nursing programmes are required to meet the NMC's standards of competence (NMC, 2010) through theoretical and clinical experience. At the point of registration, nurses are required to be both competent and confident to work in any healthcare environment (NMC, 2011).

The Nursing and Midwifery Council recognise that innovative approaches may need to be used in order to provide appropriate practice learning opportunities for students (NMC, 2011). Strong partnerships between approved education institutions and practice learning providers are vital in identifying new opportunities for practice learning and ensuring that students are supervised appropriately. 
A flexible, diverse and varied approach to placements is supported. This should echo and reflect the patient's journey through the health care system and across both hospital and community health settings (NMC, 2010). As health services are increasingly redesigned to deliver care closer to the patient's home (Sherratt et al., 2013) $25 \%-50 \%$ of the student's clinical placement time should be in the community (NMC, 2008).

Teaching and learning in the clinical setting is not a new concept and the teaching of clinical skills to student nurses is a key component of pre-registration nurse education programmes. Practice placements offer students the opportunity to develop the appropriate attitudes, psychomotor skills, knowledge and problem solving abilities required of registered practitioners, as well as enabling them to apply current theory to practice (Pollard and Hibbert, 2004).

It is a mandatory requirement that students on NMC approved preregistration nursing programmes, are assessed and supported by an identified mentor, practice teacher or supervisor (NMC, 2008). The quality of a clinical placement is seen as vital to the process of learning to be a nurse; and this is significantly influenced by the process of mentoring (Chambers, 2007). Myall et al. (2008) identify that the role of the mentor is important in helping students feel connected to a placement area.

Several studies have focused on what the role of the mentor entails. These highlight the need for mentors to be supportive, a teacher, good role model, motivator, assessor, challenger, facilitator, as well as the interpersonal aspects of the mentorship relationship and a facilitator of learning (Bray and Nettleton, 2006; Kilcullen, 2007; Nettleton and Bray, 2007).

Roxburgh et al. (2011) suggest that developing a relationship with a student over an extended period of time provided by a hub placement affords the mentor with greater incentive to invest in the student's learning. It also gives the mentor enhanced confidence when assessing the student's level of competence, providing improved consistency and reliability of assessment.

Roxburgh et al. (2011) also found that within hub placements students experienced a greater sense of belonging. Mentors reported increased belongingness in the students, and suggested that there was an increased level of confidence in the student's clinical performance, improving the overall outcome of the placement. Roxburgh (2004) suggests that, students feel better supported in the hub and spoke model of placement organisation, with a greater sense of resilience gained from a continuity of mentorship.

Communication between the hub and spoke mentors is essential to ensure continuity of assessment of the student (Roxburgh et al., 2012). The NMC (2011) recommend that supervisors in the spoke placements provide feedback to the mentor in the hub placement, Roxburgh et al. (2011) state however, that students reported little or no collaboration between staff in the hub and spoke placements, mentors on spoke placements felt unprepared, there was a lack of understanding of the function of the spoke placement amongst both mentors and students.

McLimens et al. (2013) argue that whilst hub placements provide consistency and build confidence in the student, spoke placements facilitate a better understanding of the patient journey and broaden the overall experience of the student. The function of the spoke placements is to enable the student to follow the patient throughout their health care experience.

\section{Data Collection and Methods of Analysis}

An information letter was sent to all current students on the BNurs programme outlining the purpose of the research. This letter assured the students of the voluntary, confidential and anonymous nature of the research and any findings. Students were free to withdraw at any point. Appropriate ethical approval was obtained.

Two methods of data collection were used in the project Students were contacted and asked to complete a survey through Survey
Monkey. Students were self-selecting and due to anonymous nature of the research, students who did not respond could not be contacted further. The questions on the survey arose from the group leading the research, based on their experience of practice issues in relation to the hub and spoke model. Questions were of a qualitative nature and allowed students to comment freely.

Following the completion of the qualitative survey a series of focus groups were held. Focus groups were organised using a metaplanned format adapted from the work of Davies et al. (2001) and were audio-taped and transcribed. This format ensures all participants are encouraged to fully express their views feelings and experiences. The total population was 1000 students. Out of these 367 students participated in the survey, of these 15 participated in the focus groups.

Qualitative data from the surveys and the focus groups was analysed following Creswell's (2007) spiral of analysis leading to the development of themes. This model encourages the researcher to move through the various phases of managing data in a cyclical manner rather than moving directly from one stage to the next. The process consists of immersion, coding, reflecting, organising the codes into categories which can be analysed and organised into themes which can then be further analysed. Throughout the process, the researcher reviews and reflects on the data, to ensure the findings truly reflect the views of participants thus the analysis of the data is an iterative process. The themes are supported by examples of participants' own words. To aid the development of themes Ritchie et al. (2003) suggests data be represented in a matrix enabling the researcher to check the correlation of data and themes. This is presented below.

\section{Findings}

From the data, it was apparent that the model of placement organisation provided a range of experiences which affected the learning and development of student nurses. Following Ritchie et al. (2003) model, data has been catergorised into the following themes "belongingness", "learning and development", "student mentor relationship", "quality". Some examples of the categorization process are shown in Appendix 1.

\section{Discussion of Themes}

\subsection{Belongingness}

A sense of belongingness has previously been identified as an important influence on student learning in practice (Roxburgh et al., 2011, Levett-Jones and Lathlean, 2008). Participants in this study also highlighted belongingness as a key benefit of the model of placement organisation with comments such as returning "was like coming home" and "reassured that I knew the area". Having a good relationship with the team gave them a sense of belonging and security. This sense of belonging increased the opportunity for learning and development. Participants emphasized the value of working with one mentor for long period of times as they were able to build effective relationships positively enhancing their learning and development. Often, the feeling of belonging enabled participants to "ask questions without being made to feel stupid". Participants commented that they felt enthusiastic and motivated to return to the hub and often discussed their experiences away from the hub with their mentor. This impacted positively on participant experience and satisfaction as well as on their learning.

In relation to a sense of belonging, experiences on spoke placements differed widely amongst participants with some being used as a pair of hands and others being fully involved in the team. Participant sense of belonging was affected by the quality of the placement and the relationship with the mentor. These aspects affected participant learning and development. 


\subsection{Learning and Development}

7The learning experience of participants was influenced by the NMC requirement regarding exposure to other fields of nursing. At the beginning of the programme, some participants were not aware of this requirement and found this overwhelming. However, at the end of placement experience there was general recognition that exposure to field experience had developed students' knowledge and skills.

Participants liked the variety provided by the model of placement organisation and found that many of the skills learnt on a spoke placement could be transferred back and developed further in the hub placement. Examples they provided were "skills of adaptability, communication and team working" which were all seen as important skills in nursing. There was also "increased understanding of procedures patients had undergone and the effect these had had on the patient's lives". Thus, the hub and spoke placements were seen to be complimentary to one another deepening the learning experience of participants.

One of the reasons the hub placements were seen to be particularly helpful was that they provided the participant with "plenty of time to learn essential skills" and enabled participants to "realize your capabilities". The length of time participants were on their hub placement enabled them to positively develop their expertise.

Some difficulties with spoke placements were identified and perceived as not always providing opportunity for participants for example, "I had to fight with the medical participants to get to see unusual things", "I was used as a pair of hands on some of the spokes" and "some of the spokes were a wasted experience". Others commented that they were used as a Health Care assistant whilst working in some of the spoke placements, therefore, impacting on their learning and development opportunities.

Participants recognised that their experience on a placement could be affected by their own attitude "it depends how much the participant is prepared to put in to something" and "need to use own initiative and be prepared". However, participants sometimes felt "out of their comfort zone" and if they did not feel comfortable on placement they realised this would cause difficulties. Andrews and Chiltern (2000) highlight that students learn from a variety of different ways and diverse sources. Students learning and development is not only reliant on the mentor/mentee relationship but also dependent on their own individual learning approaches.

In contrast, Kilcullen (2007) argued that the interpersonal aspect of the mentoring relationship had a major impact on the quality of learning. Where a ineffective mentor/mentee relationship was apparent, this in turn had a negative impact on the student's learning experience as a whole. Participants highlighted, that effective partnership working from all parties positively influenced their learning experience. Learning was further enhanced by their own ability to, "learn to speak up and take responsibility for their own learning" and a "need to be assertive and confident".

The hub and spoke model provided participants the opportunity to access a wide range of experiences which would not have been available in other models of placement organisation. On occasion participants found spoke placements daunting, the majority liked the "variety and experience" the model of placement organisation provided them commenting that it "showed them the full patient journey".

Hub and spoke placements were seen as complimentary to each other. From the data it is apparent that the learning and development of participants was aided by method of organising placements enabling them to view the whole patient journey and care for patients holistically.

\subsection{Student Mentor Relationships}

Mentorship is intrinsically linked to nursing and to progress to more senior positions, nurses are required to undertake a mentorship role. The quality of mentorship was of significant influence for participant learning and development. All participants are supported by an appropriate mentor throughout their programme. However, there was acknowledgement from participants that some mentors were more effective than others.

Within this study the value of high quality mentorship and a strong mentor/student relationship was seen as important by participants. Mentorship qualities such as good role model, an approachable attitude and effective communication were highlighted as characteristics which were valued. These attributes led to an effective relationship which had a positive effect on learning and development as well as the sense of belongingness.

Whilst, the importance of the relationship between participant and mentor could not be underestimated, a clash in personality between mentor and participant was made worse by the extended period of time they had to work with each other. The work of Unwin et al. (2009) highlights how negative attitudes from mentors had a significant effect a student progression and this was certainly true within this study.

From the study it was evident that participants felt mentors who were helpful, supportive and invested a lot of time and effort into developing the participants to the required level, positively affect the student experience. Participants felt that "mentors can be very enthusiastic" and "developed participant learning packs which were very helpful" which further enhanced learning and development.

\subsection{Quality}

NMC requirements relating to the revised standards of competence for pre-registration nursing (NMC, 2010) are met in full by the programme. It was apparent that the model for placement organisation provided a flexible approach which reflects the patient's journey and prepares participant nurses at the point of registration to work competently and confidently in any healthcare environment (NMC, 2011). This is further facilitated by appropriate qualified staff during spoke placements to further broaden the participant learning experience in practice.

Whilst the majority of mentors were seen to be effective and knowledgeable, it was felt that some mentors needed further training around the hub and spoke model for placement "understanding of the hub and spoke is lacking". Some participants felt they had to guide their mentor on how to complete the practice assessment documents as they had been asked questions such as "what do I need to fill in" or "where do I need to sign".

Other participants found it difficult to meet the requirements of the clinical practice document or to get practice documentation signed at the correct time. In situations like this participants felt they had to "learn to speak up and take responsibility for their own learning" and there was a "need to be assertive and confident".

Participants recognised that some mentors find it difficult to keep up to date with documentation particularly if they are not required to mentor students on a regular basis. Expectations of some mentors were not always clear and there were some inconsistencies around the different levels of knowledge and expertise expected of participants which were at times unrealistic.

Concerns with spoke placements were identified where the purpose of the placement was not always apparent. A lack of communication between the mentors on the spoke and the hub placements was highlighted with an over reliance of feedback from the participant. Occasionally it was felt that there was reluctance from some areas to support participants on spoke placements although there was recognition that supporting a participant on a spoke placement was very time consuming when they were only there for such a short period.

All groups of participants appreciated the flexible and creative approach to placements which provided this breadth of experience. It was highlighted that the hub placements provided the opportunity to develop strong and effective relationships which participants found 
satisfying which enabled participants to develop their skills and experience in a safe environment.

\section{Conclusion and Recommendations}

There were some areas identified which require further work and consideration. These relate in main to spoke placements where the value of the experience to both staff and participants should be explicit. Communication between hub placements and spoke placements should be strengthened to ensure a continuity of experience and assessment, an issue raised elsewhere in the literature (Roxburgh et al., 2011, 2012).
Participants considered that the hub and spoke model allowed for a breadth of knowledge, experience and learning which increased their confidence and enabled them to view patient care in a holistic way.

Overall, the model of placement organisation was found to be beneficial. Participants felt a sense of belonging in an area, their learning was enhanced, a broad and detailed experience was provided, team working and adaptability were enhanced and participants had opportunity to experience and understand the full patient journey. This hub and spoke model for organising student nurse placement is recommended to others.

\section{Appendix 1}

Table 1

Example of the catergorization process.

\begin{tabular}{|c|c|c|}
\hline \multirow[t]{2}{*}{ Theme } & \multicolumn{2}{|l|}{ Example of participant comments } \\
\hline & Comments about the hub & Comments about spoke \\
\hline \multirow[t]{5}{*}{ Belongingness } & \{returning to the hub\} it was like coming home & Felt like a visitor in the spoke placement \\
\hline & Comfort going back to the hub & Its only a week which is not really long enough \\
\hline & I felt part of the team & Just used as a pair of hands which is frustrating \\
\hline & Ask questions without being made to feel stupid & $\begin{array}{l}\text { It was so valuable ... they asked me what I wanted to do. One } \\
\text { of the best spokes I have been on }\end{array}$ \\
\hline & Reassured because I knew the area & \\
\hline \multirow[t]{8}{*}{ Learning and development } & Plenty of time to learn essential skills & Gives you a taster \\
\hline & Realize your capabilities & Provides an insight into how other areas work \\
\hline & \{Provided the opportunity\} to see what is elsewhere and a & Contact with other nurses and specialties \{gives you\}breadth \\
\hline & chance to see where you might want to work & and depth of knowledge experience and skills \\
\hline & You have to take responsibility for your own learning & Can't take everything in one or 2 weeks \\
\hline & & Go into overload \\
\hline & & Developed student learning packs which were very helpful \\
\hline & & I had to fight with the medical students to see unusual things \\
\hline \multirow{5}{*}{$\begin{array}{l}\text { Learning and development general } \\
\text { comment made by participants }\end{array}$} & \multicolumn{2}{|l|}{ It's like a story book } \\
\hline & \multicolumn{2}{|l|}{ You need to put things together like a jigsaw puzzle } \\
\hline & \multicolumn{2}{|l|}{ Able to see other fields of nursing which informs practice } \\
\hline & \multicolumn{2}{|c|}{ Learn to speak up and take responsibility for own learning, need to be assertive and confident. } \\
\hline & Showed them the full patient journey & \\
\hline \multirow[t]{6}{*}{ Student mentor relationships } & \multirow{2}{*}{$\begin{array}{l}\text { You build up a better relationship with your mentor in hub. } \\
\text { I don't want to go back there as I don't get on with my mentor }\end{array}$} & Spoke mentors can be very enthusiastic \\
\hline & & $\begin{array}{l}\text { Spoke mentors say you are only here for a week I don't need to } \\
\text { teach you much which made me feel not wanted }\end{array}$ \\
\hline & $\begin{array}{l}\text { Having a good relationship with my mentor makes me more } \\
\text { confident }\end{array}$ & Mentors were very welcoming \\
\hline & Mentors are fundamental to a positive experience & $\begin{array}{l}\text { I couldn't build up an effective relationship with my mentor } \\
\text { which affected my progression }\end{array}$ \\
\hline & \multicolumn{2}{|l|}{$\begin{array}{l}\text { A mentor makes or breaks your placement } \\
\text { Good mentor, good experience }\end{array}$} \\
\hline & Good mentor, good experience & \\
\hline \multirow[t]{5}{*}{ Quality } & I like the hub being a year for consistency & I was used as a pair of hands \\
\hline & I had to work hard at getting my documents signed off & Some of the spokes were a wasted experience \\
\hline & & $\begin{array}{l}\text { Interconnection between placements and connectivity between } \\
\text { hub and spokes \{are good }\end{array}$ \\
\hline & \multicolumn{2}{|c|}{ \{Lack of understanding of assessment documents\} what do I need to fill in \{or\} where do I need to sign } \\
\hline & \multicolumn{2}{|c|}{ Understanding of hub and spoke is lacking amongst mentors } \\
\hline
\end{tabular}

\section{References}

Andrews, M., Chiltern, F., 2000. Student and mentor perceptions of mentoring effectiveness. Nurse Educ. Today 20, 555-562.

Bray, L., Nettleton, P., 2006. Assessor or mentor? Role confusion in professional education. Nurse Educ. Today 27, 848-855.

Chambers, D., 2007. Is the modern NHS fit for nursing students? Br. J. Nurs. 16 (2), 74-75 Creswell, J., 2007. Qualitative inquiry and research design. Choosing Among five Approaches. Sage, Thousand Oaks.

Davies, P., Osborne, M., Williams, J., 2001. For Me or Not for Me? - That is the Question: A Study of Mature Students Decision Making and Higher Education. Stationary Office London.

Kilcullen, N., 2007. Said another way. Nurs. Forum 42 (2), 95-104.

Levett-Jones, T., Lathlean, J., 2008. Belongingness: a pre-requisite for nursing students' clinical learning. Nurse Educ. Pract. 8, 103-111.
Mclimens, A., Kenyon, L., Cheung, H., 2013. Exploring placement pathways in nurse education. Br. J. Nurs. 22 (1).

Myall, M., Levett-Jones, T., Lathlean, J., 2008. Mentorship in contemporary practice; the experiences of nursing students and practice mentors. J. Clin. Nurs. 17, 1834-1842.

Nettleton, P., Bray, L., 2007. Current mentorship schemes might be doing our students a disservice. Nurse Educ. Pract. 8, 205-212.

Nursing and Midwifery Council, 2008. Focus Group Consultation Report on a review of Pre-registration Nursing Education. NMC, London.

Nursing and Midwifery Council, 2010. Standards for Pre-registration Nursing Education. NMC, London.

Nursing and Midwifery Council, 2011. Advice and Supporting Information for Implementing NMC Standards for Pre-registration Nursing Education. NMC, London.

Pollard, C., Hibbert, C., 2004. Expanding student learning using patient pathways. Nurs. Stand. 19 (2), 40-43. 
Ritchie, J., Spencer, L., O'Connor, W., 2003. Carrying out qualitative research. In: Ritchie, J. Lewis, J. (Eds.), Qualitative Research Practice: A Guide for Social Science Students and Researchers. Sage, London.

Roxburgh, M., 2004. Undergraduate student nurses' perceptions of two practice learning models; a focus group study. Nurse Educ. Today 34, 40-46.

Roxburgh, M., Bradley, P., Lauder, W., 2011. The Development, Implementation and Evaluation of New Approaches to Practice Placements in Pre-registration Nursing Programmes; The final report. University of Sterling.
Roxburgh, M., Conlon, M., Banks, D., 2012. Evaluating hub and spoke models of practice learning in Scotland, UK; a multiple case study approach. Nurse Educ. Today 32, 782-789.

Sherratt, L., Whitehead, B., Young, A., 2013. Using more healthcare areas for placements. Nurs. Times 109 (25), 18-21.

Unwin, S., Stanley, R., Jones, A., Wainwright, P., Perkins, A., 2009. Understanding student nurse attrition: learning from the literature. Nurse Educ. Today 30 (2010), 202-207. 